\title{
BMJ Open Exposure to tobacco secondhand smoke and its associated factors among non- smoking adults in smoking-restricted and non-restricted areas: findings from a nationwide study in Malaysia
}

Kuang Hock Lim, ${ }^{1}$ Chien Huey Teh, ${ }^{1}$ Mohamad Haniki Nik Mohamed, ${ }^{2}$ Sayan Pan, ${ }^{3}$ Miaw Yn Ling, ${ }^{3}$ Muhammad Fadhli Mohd Yusoff, ${ }^{3}$ Noraryana Hassan, ${ }^{4}$ Nizam Baharom, ${ }^{5}$ Netty Darwina Dawam, ${ }^{4}$ Norliana Ismail, ${ }^{4}$ Sumarni Mohd Ghazali, ${ }^{1}$ Kee Chee Cheong, ${ }^{1}$ Kar Hon Chong, ${ }^{6}$ Hui Li Lim ${ }^{6}$

To cite: Lim KH, Teh CH, Nik Mohamed MH, et al. Exposure to tobacco secondhand smoke and its associated factors among non-smoking adults in smoking-restricted and non-restricted areas: findings from a nationwide study in Malaysia. BMJ Open 2018;8:e017203. doi:10.1136/ bmjopen-2017-017203

- Prepublication history and additional material for this paper are available online. To view these files, please visit the journal online (http://dx.doi. org/10.1136/bmjopen-2017017203).

Received 10 April 2017 Revised 5 October 2017 Accepted 30 0ctober 2017

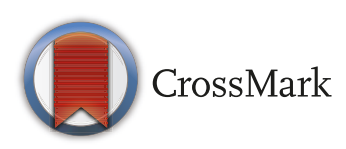

For numbered affiliations see end of article.

Correspondence to Mr Kuang Hock Lim; keelimkota@yahoo.com

\section{ABSTRACT}

Objectives Secondhand smoke (SHS) has been associated with increased morbidity and mortality. Therefore, the aims of the paper are to assess SHS exposure among non-smoking adults in Malaysia attending various smoking-restricted and non-restricted public areas according to the Control of Tobacco Product Regulations (CTPR) as well as its relationship with various sociodemographic variables.

Design Data were extracted from a cross-sectional study, the Global Adults Tobacco Survey (GATS) 2011 which involved 3269 non-smokers in Malaysia. Data was obtained through face-to-face interviews using a validated pre-tested questionnaire. Factors associated with exposure to SHS were identified via multivariable analysis.

Results The study revealed that almost two-thirds of respondents were exposed to SHS in at least one public area in the past 1 month, with a significantly higher exposure among males $(70.6 \%)$, those with higher educational attainment $(81.4 \%)$ and higher income (quintile 1\%-73.9\%). Besides, the exposure to SHS was almost four times higher in non-restricted areas compared with restricted areas under the CTPR ( $81.9 \%$ vs 22.9$)$. Multivariable analysis revealed that males and younger adults at non-restricted areas were more likely to be exposed to SHS while no significant associated factors of SHS exposure was observed in restricted areas.

Conclusions The study revealed the prevalence of SHS exposure was higher among Malaysian adults. Although smoke-free laws offer protection to non-smokers from exposure to SHS, enforcement activities in restricted areas should be enhanced to ensure strict public abidance. In addition, legislation of restricted areas should also be extended to greatly reduce the SHS exposure among non-smokers in Malaysia.

\section{INTRODUCTION}

Secondhand smoke (SHS) is composed of side stream smoke (the smoke released from the burning end of a cigarette) and exhaled

\section{Strengths and limitations of this study}

- The representativeness and adequacy of sample size as well as the high response rate enable generalisation of findings to the Malaysian population.

- Face-to-face interview approach employed in the study will increase the quality of the data.

- Under-reporting or over-reporting might occur as the period of the study was for the 1 month prior.

- Only seven 'types of public areas' were included in the study, exposure in other restricted and nonrestricted areas was not extensively investigated.

- Objective measurement of exposure to SHS among non-smokers (eg, carbon monoxide in expired breath air, cotinine (a nicotine metabolite)) was not carried out.

mainstream smoke (the smoke exhaled by the smoker). ${ }^{1}$ There are more than 200 of these chemicals, confirmed carcinogens and respiratory toxins (eg, benzene, 1,3-butadiene, formaldehyde, mercury and hydrogen cyanide) ${ }^{2}$ Exposure to SHS could affect the health of an individual. Epidemiological studies revealed that SHS exposure causes an increased risk of lung cancer by $20 \%$ to $30 \%,{ }^{3}$ heart disease by $25 \%$ to $30 \%,{ }^{4}$ stroke by up to $82 \%^{5}$ and an increased risk of other non-fatal respiratory illnesses. ${ }^{4}$ In addition it has been shown to have adverse effects on reproduction and associated with sudden infant death syndrome (SIDS). ${ }^{3}$ Furthermore, SHS has also been associated with recurrent wheezing, respiratory illnesses, decreased lung function and asthma, ${ }^{67}$ as well as chronic respiratory symptoms among adults. ${ }^{8}$ Annually 
600000 deaths were reported globally due to exposure to the SHS. ${ }^{9}{ }^{10}$

Prohibition of smoking in public areas was among the public health policies to reduce exposure to SHS in public areas apart from de-normalising smoking behaviour. Studies revealed that the implementation of this policy has reduced the exposure of adults and children in Scotland to SHS by $39 \%,{ }^{11}$ and reduced the active smoking rate among smokers. ${ }^{12}$ In addition, the implementation of smoke-free policies has also significantly reduced the salivary and urinary cotinine (a metabolite of nicotine) among non-smokers in all countries, namely the USA, Canada, Scotland, Uruguay and Ireland. ${ }^{13-18}$ Furthermore, the measurement of air quality in public areas revealed a significant reduction of several chemical components available in SHS. ${ }^{19}{ }^{20}$ Also, smoke-free laws also reduced the quantity of cigarettes smoked, ${ }^{21}$ increased the intention to quit smoking among smokers ${ }^{22}$ and increased the proportion of smoking cessation. ${ }^{23}$ More importantly, smoke-free regulation has been shown to significantly reduce the number of hospital admissions for heart attacks and asthma-related diseases, and premature births. ${ }^{24-26}$ The systematic reviews of Frazer et al in 2010 and 2016 revealed that the smoke-free policy significantly reduces the mortality related to smoking illness and improves the outcome of cardiovascular health outcome. ${ }^{27}$ The policy had been identified as a non-price measure which will reduce the mortality and morbidity due to smoking-related diseases. ${ }^{28}$

The Malaysian government through the Ministry of Health, also implemented similar measures to protect non-smokers from exposure to SHS in public areas with the introduction of smoking prohibition in public areas via the Control of Tobacco Product Regulations (CTPR) 1993. Eight areas were restricted (entertainment centres or theatres, hospitals or health clinics, public lifts, air-conditioned eating places, public vehicles, building of Island \& Peninsular Kuala Lumpur, of Malaysia property developer) and in any area of the petrol station and Esso tower building, Kuala Lumpur). This was later expanded to other public areas through the amendment of the provision to the CTPR in 1997 until 2017. ${ }^{29-37}$ The expansion of smoke-free public areas was in line with the provision of Article 8 of the Framework Convention on Tobacco Control (FCTC) ${ }^{38}$ which was rectified by the Malaysian government in 2005. As of 2017, 29 types of public areas and nine localities had been declared as smoking-restricted areas (online supplementary appendix 1). This regulation was supported by enforcement by authorised officers with frequent visits to ensure that the public abides by this provision.

Although the smoking prohibition policy had been implemented over the past two decades and studies elsewhere show its efficacy to reduce the exposure of non-smokers to SHS, ${ }^{20} 22$ the effect of smoke-free policies on SHS exposure in Malaysia has not been studied. Knowledge on the effect of exposure to SHS will assist policy makers in planning and formulating suitable policies, as well as measuring and strengthening existing policies and regulations. In addition, it will ensure the allocation of human and material resources to reduce SHS among the Malaysian public. This paper intends to narrow the knowledge gap with the illustration of SHS exposure in various public areas (restricted and non-restricted) and social demographic variation of exposure among Malaysians to SHS.

\section{METHODS}

Data for this paper was derived from the Malaysian Global Adult Tobacco Survey (GATS) which was carried out from October 2011 to January 2012. The study utilised a cross-sectional design and three-stage sampling proportionate to size to obtain a representative sample of Malaysians aged 15 years and above. The first strata consisted of 15 states in Malaysia, while the second stage was the division of urban and rural areas by each state. Enumeration blocks (EBs) which is an artificial geographical area created by the Department of Statistics consisted of 80 to 120 living quarters based on the 2010 population census, was the primary sampling unit (PSU) and living quarters (LQs) were the secondary sampling unit. One household member aged 15 years and above from the selected LQs was selected by the simple random sampling method based on a random number generated by handheld devices.

The face-to-face interview approach by trained research assistants was used to obtain data from selected respondents. Detailed information regarding the purpose of the survey was explained to the respondents. Their participation was on a voluntary basis and they had the right not to answer any question as well as withdrawing from the study at any juncture. All information given was treated as confidential and utilised for research purposes only. The interview session only started after written consent was obtained from the selected respondents. For respondents aged below 18 years' old, written consent was obtained from their parent or guardian in addition to permission by the respondent. Details of the methodology is published by Azahadi $e t$ al. ${ }^{39}$ Ethical approval was granted by the Malaysia Research Ethical Committee, Ministry of Health, Malaysia.

The study instrument was a questionnaire adopted from GATS, translated and pre-tested before use. It consists of nine components, namely social demographics, smoking status, type of tobacco product used, exposure to SHS at home, work and selected public areas, expenditure on cigarettes, knowledge of smoking hazards and SHS, intention to quit, exposure to tobacco product advertisements and information regarding the hazards of tobacco products.

The smoking status of respondents was evaluated by several items: 'Do you currently smoke?'; 'Do you use any smokeless tobacco?'; 'Do you use any sisha?'; 'Do you use any bidi?'; and 'Do you use any electronic cigarettes?' Respondents who answered 'not at all' to all the 
items were classified as 'non-smokers' while those who answered 'daily or less than daily' were categorised as 'current smokers'. Only non-smokers were included in the analysis for exposure to SHS. Exposure to SHS was determined by items 'Have you visited these public areas: (1) government offices; (2) health facilities (including a hospital or clinic); (3) public transport terminal; (4) air-conditioned shopping complex; (5) bar or night club; (6) cafe/coffee shop/bistro; and (7) non-air-conditioned restaurant during the last 1 month?' Respondents who answered 'No', 'Don't know' or 'refused to answer' were excluded from further analysis. Those who answered 'Yes' to any area/s mentioned were asked if they had seen anyone smoking during their visit(s) in any of those seven areas. Respondents who answered 'Yes' were considered as being exposed to SHS. Those who were exposed to SHS at government offices/health facilities/public transport terminal/air conditioning shopping complexes were further categorised as exposed to SHS in restricted non-smoking areas. In the same way, those who answered 'Yes' to (1) bar or night club (2) cafes/coffee shop/bistro and (3) restaurant without airconditioning were classified as exposure to SHS in non-restricted areas.

The independent variables were social demographics, namely, gender, ethnicity, educational attainment (which was divided into four categories; no formal education, primary education, secondary school and tertiary), age group (15-24 years' old, 25-44 years' old, 45-64 years' old and 65+) and locality (urban/ rural), while income level was measured using Wealth Index, a proxy measure for respondents' socioeconomic status was constructed using principal component analysis with information on household ownership of assets. ${ }^{40}$ Assets included were electricity, flush toilet, fixed telephone, cellular telephone, television, radio, refrigerator, car, moped/scooter/motorcycle, washing machine, etc. The sample was divided into quintiles, from quintile one (highest) to quintile five (lowest). Marital status of respondents was classified as single, married and widow/widower/separated.

Data was cleaned prior to analyses. It was weighted, by taking into account study design, non-response and social characteristics (gender, residence, age group, educational attainment, ethnicity) based on the Malaysia population census 2010. Descriptive statistics were utilised to describe the social demographic characteristics of the respondents. Cross-tabulation was used to describe the proportion of respondents to SHS exposure at various public places. Multivariable logistic regression was run to determine the association between various social demographic backgrounds with SHS exposure in restricted and non-restricted public areas. We reported $95 \%$ CI without $\mathrm{P}$ values as the large sample size could generate significant results even if statistical differences or associations were small. All analyses were carried out by using SPSS statistical software version 20 .

\section{RESULTS}

A total of 5112 eligible Malaysian adults aged 15 years and above were recruited into the study and 4250 of them consented to participate and completed the interview, giving a response rate of $83.1 \%$. Out of the 4250 respondents, 3269 of them were non-smokers $(76.9 \%, 95 \%$ CI 74.8 to 78.8$)$. The proportion of female non-smokers was significantly higher compared with males $(98.7 \%, 95 \%$ CI 98.0 to 99.1 vs $56.1 \%$, $95 \%$ CI 52.7 to 58.9 ). Those from the youngest (15-24 years; $83.3 \%, 95 \%$ CI 79.7 to 86.4 ) and oldest age group (65+; $85.0 \%, 95 \%$ CI 80.1 to 88.8 ) also reported a significantly higher proportion of non-smokers compared with those of 25 to 44 years' old $(71.0 \%, 95 \%$ CI 67.8 to 73.9$)$. Similarly, the proportion of non-smoking participants were higher in those with tertiary educational attainment $(84.7 \%, 95 \%$ CI 80.1 to 88.4$)$ and higher income group (quintile 1: $82.9 \%, 95 \%$ CI 79.3 to 86 and quintile 2: $80.8 \%, 95 \%$ CI 76.9 to 84.2 ) (table 1 ).

Table 2 shows that almost two-thirds of non-smokers $(63.6 \%, 95 \%$ CI 60.6 to 66.2$)$ were exposed to SHS in one or more public area during the past 1 month. The exposure among males was significantly higher compared with that among females $(70.9 \%, 95 \%$ CI 66.5 to 74.9 vs $59.1 \%, 95 \%$ CI 55.7 to 62.4$)$. In addition, respondents from urban areas, with higher educational attainment and income also reported a higher proportion of exposure to SHS. However, older respondents reported lower exposure compared with their younger counterparts (15-24 years, $72.1 \%$, 95\% CI 67.4 to 76.3 ; 25-44 years, $67.9 \%, 95 \%$ CI $63.8 \%, 95 \%$ CI 63.8 to 71.5 ; 45-64 years, $54.4 \%$, 95 CI\% 49.9-58.8; and $65+, 37.3 \%$, $95 \%$ CI $29.1 \%$ to $46.1 \%$ ).

Exposure of non-smokers to SHS was significantly higher in non-restricted public areas compared with restricted areas, in which the proportion of exposure was approximately four times higher than that reported in restricted areas $(81.9 \%, 95 \%$ CI 79.5 to 84.1 vs $22.9 \%$, 95\% CI 20.4 to 25.5). Further analysis of exposure to SHS in restricted areas revealed that the level of exposure was significantly lower in healthcare facilities (8.7\%, 95\% CI 6.9 to 10.8) compared with indoor shopping complexes $(13.6 \%, 95 \%$ CI 11.7 to 15.7$)$, government offices $(20.0 \%, 95 \%$ CI 16.4 to 24.2$)$ and public transport (27.9\%, 95\% CI 22.5 to 34.0$)$. No significant difference was observed among all social demographic characteristics to SHS in non-restricted areas except for the younger age group of $15-24$ years $(30.2 \%$, 95\% CI 25.6 to 35.3 ). The study also revealed that the level of SHS exposure to the three non-restricted smoking areas were almost similar for all respondents from different social demographic backgrounds (table 3)

Multivariable logistic regression analysis revealed that the likelihood of exposure to SHS in restricted public areas were almost similar across all social demographic variables, while for the non-restricted area, non-smokers from the younger age group (15-24, Adjusted odd ratio (AOR) 5.07, 95\% CI 2.18 to 11.7 ; 25-44. AOR 3.12, 


\begin{tabular}{|c|c|c|c|c|c|}
\hline \multirow[t]{2}{*}{$\begin{array}{l}\text { Demographic } \\
\text { characteristic }\end{array}$} & \multirow[t]{2}{*}{$n^{*}$} & \multirow[t]{2}{*}{$\begin{array}{l}\mathrm{N} \dagger \text { (in } \\
\text { thousands) }\end{array}$} & \multirow[t]{2}{*}{$\%$} & \multicolumn{2}{|c|}{$95 \mathrm{Cl}$} \\
\hline & & & & Lower & Upper \\
\hline \multicolumn{6}{|l|}{ Gender } \\
\hline Male & 1144 & 5938 & 56.1 & 52.7 & 59.4 \\
\hline Female & 2125 & 9887 & 98.7 & 98.0 & 99.1 \\
\hline \multicolumn{6}{|c|}{ Age group (years) } \\
\hline $15-24$ & 605 & 4745 & 83.3 & 79.7 & 86.4 \\
\hline $25-44$ & 1284 & 6063 & 71.0 & 67.8 & 73.9 \\
\hline $45-64$ & 1026 & 3764 & 77.3 & 74.1 & 80.2 \\
\hline $65+$ & 354 & 1252 & 85.0 & 80.1 & 88.8 \\
\hline \multicolumn{6}{|l|}{ Residence } \\
\hline Urban & 1616 & 11485 & 77.3 & 74.6 & 79.8 \\
\hline Rural & 1653 & 4340 & 75.7 & 73.3 & 78.0 \\
\hline \multicolumn{6}{|l|}{ Education level } \\
\hline $\begin{array}{l}\text { Less than } \\
\text { primary }\end{array}$ & 520 & 1605 & 80.3 & 75.8 & 84.1 \\
\hline Primary & 834 & 3170 & 75.7 & 72.1 & 79.0 \\
\hline $\begin{array}{l}\text { Second/high } \\
\text { school }\end{array}$ & 1031 & 4770 & 74.9 & 71.9 & 77.6 \\
\hline $\begin{array}{l}\text { College or } \\
\text { above }\end{array}$ & 264 & 1472 & 84.7 & 80.1 & 88.4 \\
\hline \multicolumn{6}{|l|}{ Ethnicity } \\
\hline Malay & 1931 & 9143 & 75.4 & 72.7 & 77.9 \\
\hline Chinese & 553 & 3226 & 84.6 & 80.5 & 88.0 \\
\hline Indian & 213 & 1552 & 80.4 & 73.6 & 85.8 \\
\hline Other & 572 & 1903 & 70.0 & 64.7 & 74.9 \\
\hline \multicolumn{6}{|c|}{ Quintile income level } \\
\hline Q 1 & 698 & 4941 & 82.9 & 79.3 & 86.0 \\
\hline Q 2 & 689 & 3832 & 80.8 & 76.9 & 84.2 \\
\hline Q 3 & 601 & 3004 & 71.8 & 67.1 & 76.0 \\
\hline Q 4 & 628 & 2281 & 73.0 & 68.1 & 77.5 \\
\hline Q 5 & 603 & 1578 & 68.0 & 62.9 & 72.7 \\
\hline
\end{tabular}

${ }^{*} n$, sample.

$\dagger \mathrm{N}$, estimated population.

95\% CI 1.51 to $6.45 ; 45-64$, AOR 2.08 , 95\% CI 1.10 to $3.93 ; 65+$ as reference) and males (AOR 1.46, 95\% CI 1.03 to 2.05 ) were more likely to be exposed to SHS in the past 1 month (table 4).

\section{DISCUSSIONS}

This is, to our knowledge, the first report on exposure to SHS in various public areas among a representative sample of the Malaysian adult population after two decades of antismoking law implementation. The study reveals that almost two out of three $(66.7 \%)$ Malaysian adolescents (below the age of 19 years' old) and adults were exposed to SHS in at least one public area investigated during the 1 month prior to the study. This is similar $(66 \%)$ to that reported in
Table 2 Exposure to SHS in at least one public place by social demographic

\begin{tabular}{|c|c|c|c|c|c|}
\hline \multirow[t]{2}{*}{$\begin{array}{l}\text { Demographic } \\
\text { characteristic }\end{array}$} & \multirow[t]{2}{*}{$\mathbf{n}^{*}$} & \multirow[t]{2}{*}{$\begin{array}{l}\mathrm{N}+\text { (in } \\
\text { thousands) }\end{array}$} & \multirow[t]{2}{*}{$\%$} & \multicolumn{2}{|c|}{$95 \mathrm{Cl}$} \\
\hline & & & & Lower & Upper \\
\hline \multicolumn{6}{|l|}{ Gender } \\
\hline Male & 667 & 3847 & 70.9 & 66.5 & 74.9 \\
\hline Female & 972 & 5320 & 59.1 & 55.2 & 62.4 \\
\hline \multicolumn{6}{|c|}{ Age group (years) } \\
\hline $15-24$ & 347 & 3139 & 72.1 & 67.4 & 76.3 \\
\hline $25-44$ & 749 & 3759 & 67.9 & 63.8 & 71.5 \\
\hline $45-64$ & 441 & 1846 & 54.4 & 49.9 & 58.8 \\
\hline $65+$ & 102 & 423 & 37.3 & 29.1 & 46.1 \\
\hline \multicolumn{6}{|l|}{ Residence } \\
\hline Urban & 945 & 7182 & 67.9 & 64.5 & 71.2 \\
\hline Rural & 694 & 1985 & 51.6 & 47.8 & 55.3 \\
\hline \multicolumn{6}{|l|}{ Education level } \\
\hline $\begin{array}{l}\text { Less than } \\
\text { primary }\end{array}$ & 142 & 5010 & 34.0 & 27.8 & 40.7 \\
\hline Primary & 493 & 2615 & 59.3 & 54.9 & 63.6 \\
\hline $\begin{array}{l}\text { Second/high } \\
\text { school }\end{array}$ & 764 & 4448 & 68.1 & 64.2 & 71.7 \\
\hline $\begin{array}{l}\text { College or } \\
\text { above }\end{array}$ & 237 & 1590 & 81.4 & 75.6 & 86.1 \\
\hline \multicolumn{6}{|l|}{ Ethnicity } \\
\hline Malay & 946 & 5083 & 63.1 & 59.6 & 66.4 \\
\hline Chinese & 948 & 2192 & 70.8 & 65.9 & 76.0 \\
\hline Indian & 130 & 1004 & 68.6 & 59.7 & 76.3 \\
\hline Other & 227 & 887 & 49.1 & 42.6 & 55.6 \\
\hline \multicolumn{6}{|c|}{ Quintile income level } \\
\hline Q1 & 476 & 3406 & 73.9 & 69.1 & 78.2 \\
\hline Q 2 & 406 & 2040 & 69.4 & 64.7 & 73.7 \\
\hline Q 3 & 308 & 1705 & 62.6 & 57.1 & 67.8 \\
\hline Q 4 & 267 & 1085 & 52.2 & 46.1 & 58.2 \\
\hline Q 5 & 179 & 511 & 36.3 & 30.6 & 42.4 \\
\hline
\end{tabular}

${ }^{*} n$, sample.

$\dagger \mathrm{N}$, estimated population.

Spain, ${ }^{41}$ but lower compared with that reported by Xiao et $a t^{42}$ among non-smokers aged 15 years and above in China: $72.4 \%$ (95\% CI 70.4 to 74 ). Interestingly, it is higher than that reported among non-smokers in Cambodia ${ }^{43}$ and the $\mathrm{EU},{ }^{44}$ which were $37.4 \%$ and $29.0 \%$, respectively. The proportion of SHS exposure by gender was almost two times higher compared with that reported globally (70\% vs $33 \%$ for males; $59 \%$ vs $31 \%$ for females). ${ }^{45}$ The different proportion of exposure might be due to different social norms in related countries, as an existing anti-smoking norm might reduce the likelihood of smoking in public areas. In addition, different anti-smoking laws/policies might be another contributing factor for this difference in the proportion of exposure to SHS. Hence, further studies are required to 


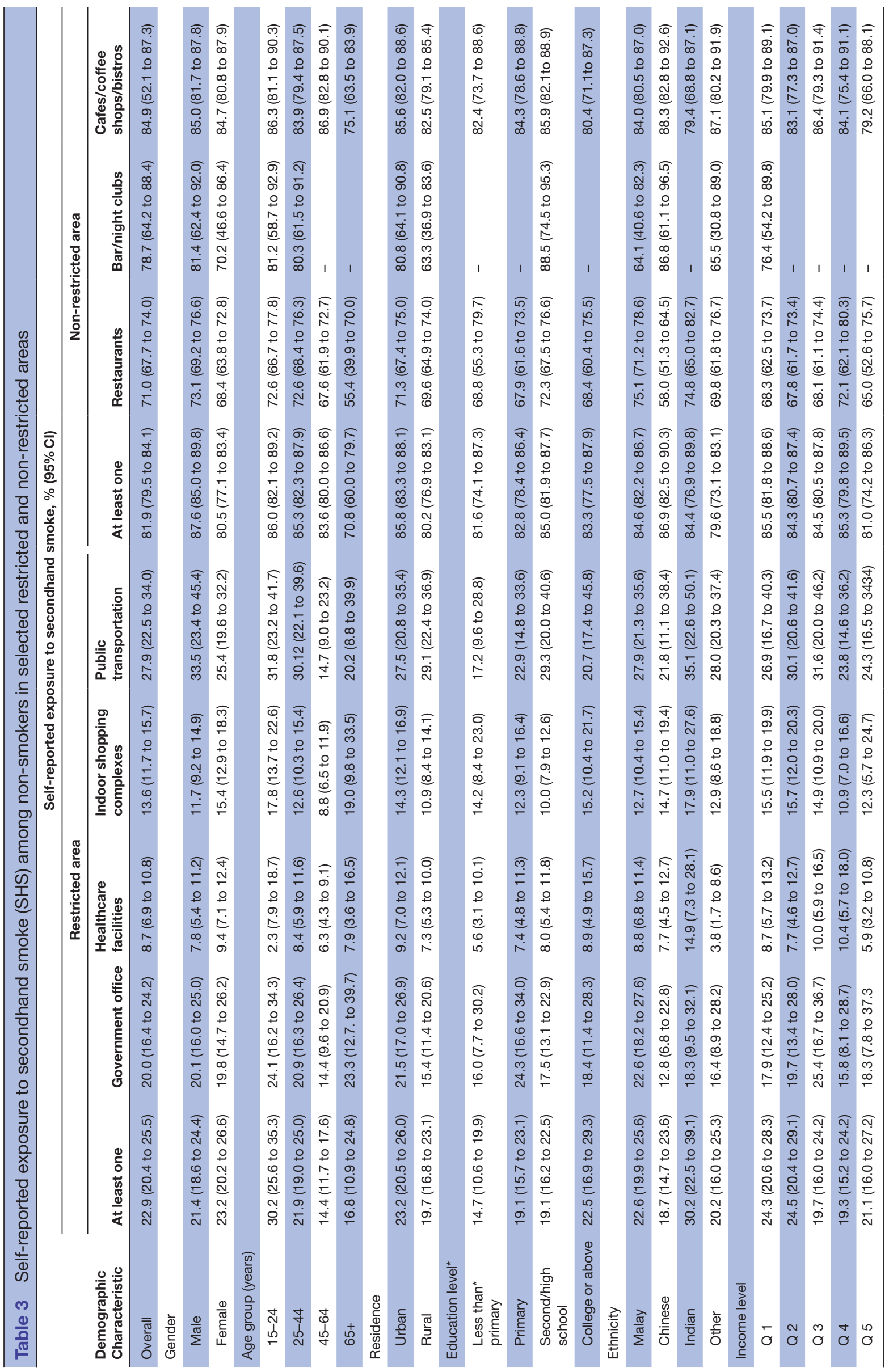


Table 4 Multivariable analysis of non-smoker exposure to secondhand smoke in restricted and non-restricted public area

Exposure to secondhand smoke

\begin{tabular}{|c|c|c|c|c|c|c|}
\hline \multirow[b]{3}{*}{ Variable } & \multicolumn{3}{|c|}{ Restricted area } & \multicolumn{3}{|c|}{ Non-restricted area } \\
\hline & \multirow[t]{2}{*}{ AOR } & \multicolumn{2}{|c|}{$95 \% \mathrm{Cl}$} & \multirow[t]{2}{*}{ AOR } & \multicolumn{2}{|c|}{$95 \% \mathrm{Cl}$} \\
\hline & & Lower & upper & & Lower & Upper \\
\hline \multicolumn{7}{|l|}{ Gender } \\
\hline Female & Ref & & & Ref & & \\
\hline Male & 0.89 & 0.66 & 1.12 & 1.46 & 1.03 & 2.05 \\
\hline \multicolumn{7}{|l|}{ Locality } \\
\hline Urban & Ref & & & Ref & & \\
\hline Rural & 0.90 & 0.67 & 1.21 & 0.79 & 0.57 & 1.10 \\
\hline \multicolumn{7}{|l|}{ Ethnicity } \\
\hline Chinese & Ref & & & Ref & & \\
\hline Malay & 1.18 & 0.80 & 1.73 & 0.70 & 0.48 & 1.03 \\
\hline Indian & 1.72 & 0.98 & 1.64 & 0.86 & 0.46 & 1.59 \\
\hline Others & 1.03 & 0.65 & 1.64 & 0.49 & 0.28 & 0.85 \\
\hline \multicolumn{7}{|l|}{ Education attainment } \\
\hline College and above & Ref & & & Ref & & \\
\hline No formal education & 0.56 & 0.29 & 1.08 & 1.62 & 0.78 & 3.40 \\
\hline Primary school & 0.69 & 0.44 & 1.07 & 1.16 & 0.69 & 1.98 \\
\hline Secondary school & 0.64 & 0.43 & 0.94 & 1.14 & 0.76 & 1.74 \\
\hline \multicolumn{7}{|l|}{ Age group } \\
\hline $65+$ & Ref & & & Ref & & \\
\hline $15-24$ & 1.59 & 0.68 & 3.75 & 5.07 & 2.18 & 1.73 \\
\hline $25-44$ & 1.32 & 0.70 & 2.50 & 3.12 & 1.51 & 6.45 \\
\hline $45-64$ & 0.82 & 0.45 & 1.49 & 2.08 & 1.10 & 3.93 \\
\hline \multicolumn{7}{|l|}{ Marital status } \\
\hline Married & Ref & & & Ref & & \\
\hline Single & 1.36 & 0.86 & 2.15 & 0.92 & 0.51 & 1.65 \\
\hline Widow/er/separated & 1.24 & 0.76 & 2.03 & 0.68 & 0.44 & 1.06 \\
\hline \multicolumn{7}{|l|}{ Quintile income group } \\
\hline Q1 & Ref & & & Ref & & \\
\hline Q 2 & 1.12 & 0.79 & 1.60 & 0.95 & 0.65 & 1.39 \\
\hline Q 3 & 1.05 & 0.70 & 1.57 & 1.04 & 0.67 & 1.64 \\
\hline Q 4 & 0.74 & 0.49 & 1.13 & 1.15 & 0.65 & 2.03 \\
\hline Q 5 & 1.05 & 0.66 & 1.69 & 0.74 & 0.39 & 1.38 \\
\hline
\end{tabular}

elucidate the real factors for the differences in exposure to SHS reported.

There were no significant differences in SHS exposure in restricted areas among urban and rural dwellers, after controlling for potential confounders. In contrast, urban dwellers were significantly more likely to be exposed to SHS in non-restricted areas compared with their rural counterparts. This could be possibly due to the fact that restaurants, bar/night clubs and cafes/coffee shops/ bistros were less readily accessible in rural areas. On the other hand, no significant differences in SHS exposure were observed across ethnic categories, in both restricted and non-restricted areas. One of the possible explanations is that, regardless of ethnicity, most of the restricted areas (healthcare facilities, indoor shopping complexes and public transport) and non-restricted areas (restaurants and cafes/coffee shops/bistros) were commonly visited or patronised by Malaysians.

Respondents from the younger age group reported higher exposure to SHS in non-restricted areas. This finding is in line with that by $\mathrm{Li} e t a t^{46}$ among women in China, in which the level of exposure decreased from $66.8 \%$ in those aged 18 to 24 to $38.9 \%$ among those aged 65 and above. The finding might be because the 
respondents of the younger age group mostly consist of those who are productive and economically active, therefore they are more mobile and visit public areas more often compared with their counterparts from lower education, lower income and older age groups. Furthermore, the public areas under investigation (eg, coffee houses and bistro) were premises which were tailored to attract the younger age group.

Male respondents were more likely to be exposed to SHS in non restricted areas in univariate and multivariate analysis compared with females. The finding is in line with Rudatsikira $e t a t^{43}$ ), Li et $a l^{46}$ and Desalu $e t a t^{47}$ ) who reported a higher proportion of SHS exposure among non-smoking males in Cambodian adults residing in two cities in Nigeria and adults in north-east China, respectively. This might be due to males being more mobile compared with females in view of their nature of occupation which require them to travel more. In Malaysia, males tend to socialise more compared with females as it is reflects the patriarchal society of Malaysia. In addition, non-smoking males might befriend those who are smokers in view of the high prevalence of smokers among males (45\%) in Malaysia and therefore increases the likelihood of exposure to secondhand smoke. ${ }^{48}$

Exposure to SHS was significantly lower in restricted areas compared with non-restricted areas. This is consistent with several previous studies. ${ }^{19}{ }^{49-53}$ All studies revealed that laws significantly reduced exposure to SHS in a variety of public places, especially bars, restaurants and outdoor patios of these premises. These reductions in public-place exposure are observed for both smokers and non-smokers. Multivariable analysis, which showed no difference in the likelihood among various socioeconomic backgrounds to SHS exposure support the notion that smoke-free areas offer protection to non-smokers from SHS exposure (table 5).

Among the restricted areas, non-smokers reported the lowest exposure to SHS in health facilities, followed by air-conditioned shopping centres, government offices and public transport. Similar findings were also reported from the Global Adult Tobacco Survey (GATS) in the Philippines in $2010 .^{54}$ This could be due to the majority of health personnel being aware of the dangers of smoking and SHS which translate to their attitude and behaviour towards smoking, therefore creating a non-smoking social norm among their fraternity. This reduces the likelihood of smoking behaviour and increases the advising of those who smoke in the hospitals/health facilities to smoke elsewhere. The respondents who visited the hospitals/health facilities usually consist of those who seek treatment, hence their health condition might not permit them to continue their smoking behaviour. Teh $e t a \varphi^{5}$ also reported that a majority of the public perceived that hospitals/health facilities were premises which provided treatment and therefore inappropriate for anyone to practice an unhealthy lifestyle. In addition, respondents who visit the hospitals were mostly from the older age group with less likelihood to be smokers in view of the lower prevalence of smoking among older Malaysians $(16.4 \%)^{56}$

The low prevalence of SHS exposure among non-smokers in the shopping centres (approximately one in ten or $10 \%$ ) might be due to central air-conditioning systems utilised in most Malaysian shopping centres whereby any cigarette smoking within the premises created a nuisance to the public, and their reactions serve as a deterrent for smokers to smoke. In addition, the management of these shopping centres usually try to take all necessary measures to retain their customers through a conducive and cosy environment for shopping. One of the approaches was to ensure the conducive environment for visitors via a smoke-free environment. In addition, owners' fear of being fined for having people smoking in their premises could be another possible reason for the finding in this study.

More than one-fifth and almost one-third of non-smokers were exposed to SHS in the past 1 month during their visit to a government office and use of public transport, respectively. The high exposure was rather surprising in view of the area and the facility having been designated as smoke-free over the past 20 years. This is a clear indication of non-compliance to the legislation.

Among the smoking-restricted areas, it is noteworthy that public transport and government offices had been reported to have the highest level of SHS exposure. These findings may indicate a debilitated enforcement of smokefree regulations in those areas. In Malaysia, the Environmental Health Officers or Assistant Environmental Health Officers (EHO/AEHO) who are involved in law enforcement, are unable to perform their task as regularly and frequently as needed as they are overwhelmed by other routine surveillance activities for both communicable and non-communicable diseases. ${ }^{57}$ However, further investigations from multiple angles, such as the person who smokes in the restricted areas (either government officers in government premises or drivers of public transport), level of awareness on SHS exposure among the public and assessment on the level of enforcement activities as well as adequacy of enforcement officers in anti-smoking programmes are urgently required to elucidate the contributing factors for the present findings.

Of note, although the present study analysed 6-year-old data from GATS 2011, however, this should not be an issue of concern that the data is out of date and may not reflect the current smoking phenomena in Malaysia, since the smoking profile among Malaysian adults was comparably similar in GATS 2011 and the National Health and Morbidity Survey (NHMS) in 2015. For instance, the overall prevalence of smoking was $23.1 \%$ (95\% CI) in 2011 compared with $22.8 \%$ (95\% CI). Moreover, the prevalence of smoking also did not vary significantly by socio-demographics in 2011 and 2015. In addition, we have analysed the smoking profile in Malaysia from 1985 to 2015: the results showed that Malaysia is still at Stage II of the cigarette epidemic model developed by Lopez $e t a t^{58}$ which evidently indicated that the smoking 


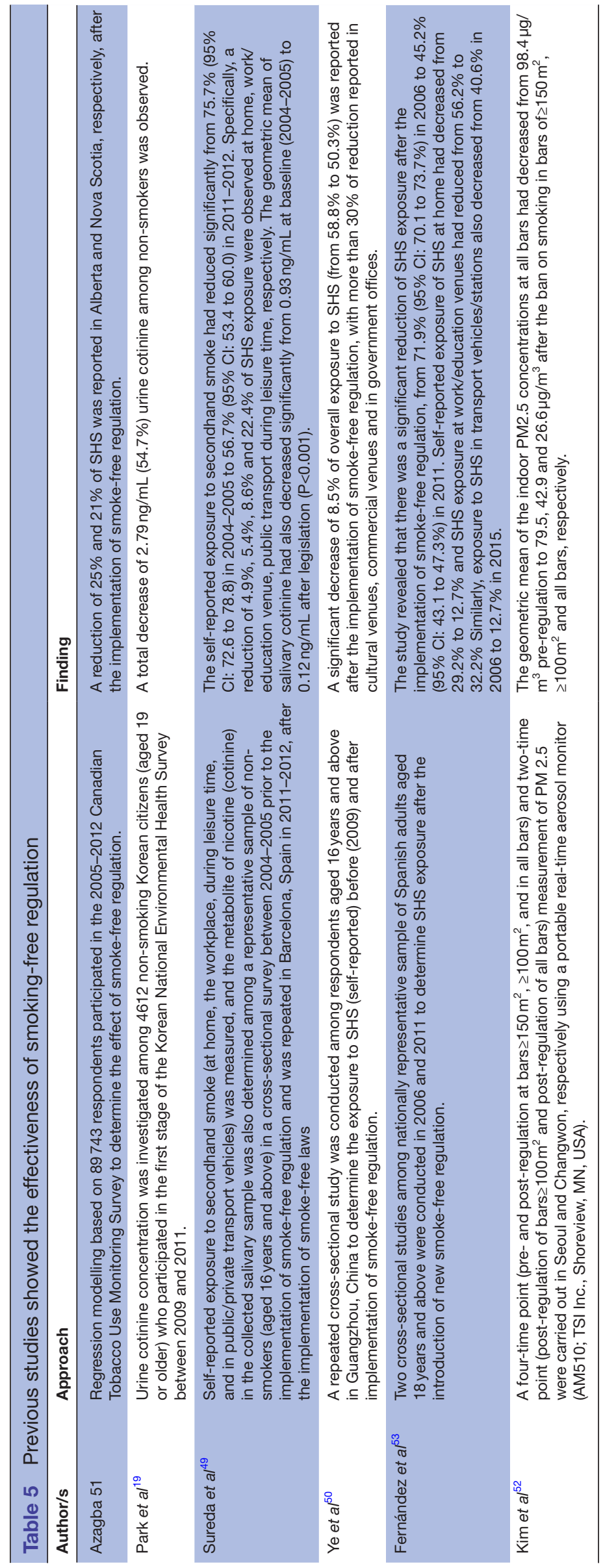


prevalence and profile have not changed since 1985. Therefore the present findings which derived from the GATS in 2011 is still valid and of relevant. Besides, there was also evidence that smoke-free regulation in Malaysia had not changed substantially from 1993 to 2017 (online supplementary appendix 1). Therefore, the effect of the variation in smoke-free legislation over the years against SHS exposure would not pose a great concern in view of the insignificant changes in smoke-free regulations in Malaysia.

The strengths of the present study were the representativeness and adequacy of sample size as well as a high response rate which enabled generalisation of findings to the Malaysian population. Furthermore, a face-to-face interview approach compared with self-administered could also increase the quality of the data. Nonetheless, the present study was also subjected to few limitations. First, under-reporting or over-reporting might occur as this was a cross-sectional study at a 1-month period. Second, a comprehensive observation and concrete conclusion on SHS exposure in smoking-restricted and non-restricted areas could not be made due to the inclusion of only seven types of public areas in the present study. Third, the exposure to SHS was determined based on the observation by respondents which was rather subjective compared with objective measurement of SHS exposure. Therefore, future studies should include more public areas (both smoking-restricted and non-restricted) and employ objective measurement for SHS exposure such as measurement of carbon monoxide or cotinine (a nicotine metabolite) in the expired breath air, or measurement of air quality for chemicals related to SHS. However, previous studies had found satisfactory validity of self-reported SHS exposure. ${ }^{5960}$

The findings from the study add to the body of evidence that the prohibition of smoking in public areas will reduce the exposure to SHS. ${ }^{19} 2041$ Therefore, more public areas should be nominated as non-smoking areas to further reduce the exposure to SHS among the public and to create an environment which is not conducive for smoking. However, the sizeable reported exposure to SHS by non-smokers demands stricter and more frequent enforcement of the provision under the current antismoking law to ensure all restricted areas are to be $100 \%$ smoke-free.

\section{Author affiliations \\ ${ }^{1}$ Institute for Medical Research, Kuala Lumpur, Malaysia \\ ${ }^{2}$ Kuliyyah of Pharmacy, International Islamic University Malaysia, Pahang, Malaysia \\ ${ }^{3}$ Institute of Public Health, Kuala Lumpur, Wilayah Persekutuan, Malaysia \\ ${ }^{4}$ Disease Control Division, Ministry of Health Malaysia, Putrajaya, Malaysia \\ ${ }^{5}$ Faculty of Medicine and Health Sciences, Universiti Sains Islam Malaysia, Kuala \\ Lumpur, Wilayah Persekutuan Kuala Lumpur, Malaysia \\ ${ }^{6}$ Hospital Sultan Haji Ahmad Shah, Temerloh, Pahang, Malaysia}

Acknowledgements We would like to thank the Director-General of Health Malaysia for his permission to publish this paper. We would also like to thank those who were involved in the study and who assisted in the collection and management of the data for their support and cooperation.
Contributors LKH, TCH and MHNM, LHL wrote the manuscript, SMG and KCC carried out statistical analysis, SP, MFY, LMY designed the study, NH, NZ, NDD and $\mathrm{NI}$ were responsible for data collection and coordination of the study. CKH managed and cleaned the data. LKH, TCH and LHL were involved in interpretation and implications of the analysis. All authors contributed to developing the manuscript, and read and approved the final version.

Funding The project was funded by the Ministry of Health, Malaysia.

Competing interests None declared.

Patient consent Obtained.

Ethics approval Malaysia Research Ethical Committee, Ministry of Health, Malaysia.

Provenance and peer review Not commissioned; externally peer reviewed.

Data sharing statement № additional data are available.

Open Access This is an Open Access article distributed in accordance with the Creative Commons Attribution Non Commercial (CC BY-NC 4.0) license, which permits others to distribute, remix, adapt, build upon this work non-commercially, and license their derivative works on different terms, provided the original work is properly cited and the use is non-commercial. See: http://creativecommons.org/ licenses/by-nc/4.0/

(c) Article author(s) (or their employer(s) unless otherwise stated in the text of the article) 2018. All rights reserved. No commercial use is permitted unless otherwise expressly granted.

\section{REFERENCES}

1. World Health Organization (WHO) / International Agency for Research on Cancer (IARC). Tobacco smoke and involuntary smoking: summary of data reported and evaluation. Geneva: WHO, 2004.

2. World Health Organization. Legislating for smoke free workplaces. Copenhagen: WHO, 2006

3. U.S. Department of Health and Human Services. The health consequences of involuntary exposure to tobacco smoke:a report of the surgeon general. Maryland: U.S. Department of Health and Human Services, Centers forDisease Control and Prevention, Coordinating Center for Health Promotion,National Center for Chronic Disease Prevention and Health Promotion, Officeon Smoking and Health, 2006.

4. U.S. Department of Health and Human Services. Let's make the next generation tobacco-free: Your guide to the 50th anniversary surgeon general's report on smoking and health. Atlanta: U.S.Department of Health and Human Services, Centers for Disease Control and Prevention, National Center for Chronic Disease Prevention and Health Promotion, Office on Smoking and Health, 2014. (accessed 11 Jan 2016)

5. Bonita R, Duncan J, Truelsen T, et al. Passive smoking as well as active smoking increases the risk of acute stroke. Tob Control 1999;8:156-60.

6. Akinbami LJ, Kit BK, Simon AE. Impact of environmental tobacco smoke on children with asthma, US, 2003-2010. Acad Pediatr 2013;13:508-16.

7. Wang Z, May SM, Charoenlap S, et al. Effects of secondhand smoke exposure on asthma morbidity and health care utilization in children: a systematic review and meta-analysis. Ann Allergy Asthma Immunol 2015;115:396-401.

8. Laden F, Chiu YH, Garshick E, et al. A cross-sectional study of secondhand smoke exposure and respiratory symptoms in noncurrent smokers in the U.S. trucking industry: SHS exposure and respiratory symptoms. BMC Public Health 2013;13:93.

9. World Health Organization. WHO report on the Global Tobacco Epidemic 2008: the MPOWER package. Geneva: World Health Organization, 2008.

10. Oberg M, Jaakkola MS, Woodward A, et al. Worldwide burden of disease from exposure to second-hand smoke: a retrospective analysis of data from 192 countries. Lancet 2011;377:139-46.

11. Haw SJ, Gruer L. Changes in exposure of adult non-smokers to secondhand smoke after implementation of smoke-free legislation in Scotland: national cross sectional survey. BMJ 2007;335:549.

12. Frazer $\mathrm{K}$, Callinan JE, McHugh J, et al. Legislative smoking bans for reducing harms from secondhand smoke exposure, smoking prevalence and tobacco consumption. Cochrane Database Syst Rev 2016;2:CD005992. 
13. Jensen JA, Schillo BA, Moilanen MM, et al. Tobacco smoke exposure in nonsmoking hospitality workers before and after a state smoking ban. Cancer Epidemiol Biomarkers Prev 2010;19:1016-21.

14. Farrelly MC, Nonnemaker JM, Chou R, et al. Changes in hospitality workers' exposure to secondhand smoke following the implementation of New York's smoke-free law. Tob Control 2005;14:236-41.

15. Bondy SJ, Zhang B, Kreiger N, et al. Impact of an indoor smoking ban on bar workers' exposure to secondhand smoke. J Occup Environ Med 2009;51:612-9.

16. Mulcahy M, Evans DS, Hammond SK, et al. Secondhand smoke exposure and risk following the Irish smoking ban: an assessment of salivary cotinine concentrations in hotel workers and air nicotine levels in bars. Tob Control 2005;14:384-8.

17. Akhtar PC, Currie DB, Currie $\mathrm{CE}$, et al. Changes in child exposure to environmental tobacco smoke (CHETS) study after implementation of smoke-free legislation in Scotland: national cross sectional survey. BMJ 2007:335:545-9.

18. Blanco-Marquizo A, Goja B, Peruga A, et al. Reduction of secondhand tobacco smoke in public places following national smoke-free legislation in Uruguay. Tob Control 2010;19:231-4.

19. Park JH, Lee CK, Kim KH, et al. Decrease in the urine cotinine concentrations of Korean non-smokers between 2009 and 2011 following implementation of stricter smoking regulations. Int $\mathrm{J} \mathrm{Hyg}$ Environ Health 2016;219:123-8.

20. Gleich F, Mons U, Pötschke-Langer M. Air contamination due to smoking in German restaurants, bars, and other venues-before and after the implementation of a partial smoking ban. Nicotine Tob Res 2011;13:1155-60.

21. Lee JT, Glantz SA, Millett C. Effect of smoke-free legislation on adult smoking behaviour in England in the 18 months following implementation. PLoS One 2011;6:e20933.

22. Brown A, Moodie C, Hastings G. A longitudinal study of policy effect (smoke-free legislation) on smoking norms: ITC Scotland/United Kingdom. Nicotine Tob Res 2009;11:924-32.

23. Gorini G, Gasparrini A, Tamang E, et al. Prevalence of second-hand smoke exposure after introduction of the Italian smoking ban: the Florence and Belluno survey. Tumori 2008;94:798-802.

24. Institute of Medicinec. Second-hand smoke exposure andcardiovascular effects making sense of the evidence. USA: Institute of Medicine, 2009.

25. Sims M, Mindell JS, Jarvis MJ, et al. Did smokefree legislation in England reduce exposure to secondhand smoke among nonsmoking adults? Cotinine analysis from the Health Survey for England. Environ Health Perspect 2012;120:425-30.

26. Kabir Z, Connolly GN, Alpert HR. Secondhand smoke exposure and neurobehavioral disorders among children in the United States. Pediatrics 2011;128:263-70.

27. Frazer K, McHugh J, Callinan JE, et al. Impact of institutional smoking bans on reducing harms and secondhand smoke exposure. Cochrane Database Syst Rev 2016:CD011856.

28. Joossens L, Raw M. The tobacco control scale: a new scale to measure country activity. Tob Control 2006;15:247-53.

29. Government of Malaysia (2005). Food act 1993: Control of tobacco product regulations. 2004. http://www.tobaccocontrollaws.org/files/ live/Malaysia/Malaysia\%20-\%20TC\%20Regs\%202004.pdf

30. Government of Malaysia (2008). Federal government gazette: Declaration of non-smoking areas. 2011. http://www. tobaccocontrollaws.org/files/live/Malaysia/Malaysia\%20-\%20Dec.\% 20of\%20Non-Smoking\%20Area\%202011.pdf

31. Government of Malaysia (2012). Food act 1983: control of tobacco product (amendment) regulation. 2012. http://www. tobaccocontrollaws.org/files/live/Malaysia/Malaysia\%20-\%20Dec.\% 20of\%20Non-Smoking\%20Area\%202012.pdf

32. Government of Malaysia. Declaration of non-smoking area. 2012 http://www.federalgazette.agc.gov.my/outputp/pub_20121001_ Perisytih aran\%20Kaw\%20Larangan\%20Merokok\%202012.pdf (accessed 5 Sep 2017).

33. Government of Malaysia. Declaration of non-smoking area. 2014 http://www.federalgazette.agc.gov.my/outputp/pub_20140618_ P.U.\%20(B)\%20312\%20-\%20Perisytiharan\%20Larangan\% 20Merokok.pdf (accessed 5 Sep 2017).

34. Government of Malaysia. Declaration of non-smoking area. 2015. http://www.federalgazette.agc.gov.my/outputp/pub_20150709_ P.U.\%20(B)\%20273\%20\%20Perisytiharan\%20Kawasan\% 20Larangan\%20Merokok\%202015.pdf (accessed 5 Sep 2017).
35. Government of Malaysia. Declaration of non-smoking area. 2017. http://www.federalgazette.agc.gov.my/outputp/pub_20170414_P. U.\%20(\%20B)\%20195\%202017.pdf

36. Government of Malaysia. Declaration of non-smoking area. 2017 http://www.federalgazette.agc.gov.my/outputp/pub_20170515_P. U.(B)25 32017.pdf

37. Government of Malaysia. Declaration of non-smoking area. 2017. http://www.federalgazette.agc.gov.my/outputp/pub_20170621 Draf 20Perisytiharan\%20kawasan\%20larangan\%20merokok\%20 Terengganu\%202 017. pdf

38. World Health Organization. WHO framework convention on tobacco control. Geneva: WHO, 2003. (accessed 26 Mar 2016).

39. Azahadi O, Fadhli MY M, Tee GH, et al. Methodology of Global Adult Tobacco Survey (GATS), Malaysia, 2011. Int J Pub Heal Res 2015:3:297-305.

40. World Health Organization (2010). Economic of tobacco toolkit: economic analysis of demand using data from the Global Adult Tobacco Surveys. Geneva: WHO, 2010.

41. Paradela C, Pérez-Ríos M, Ruano-Ravina A, et al. Exposure to environmental tobacco smoke in Chaves after the implementation of the law 37/2007. A cross-sectional study in two healthcare settings. Rev Port Pneumol 2013;19:168-74.

42. Xiao L, Yang Y, Li Q, et al. Population-based survey of secondhand smoke exposure in China. Biomed Environ Sci 2010;23:430-6.

43. Rudatsikira EM, Knutsen SF, Job JS, et al. Exposure to environmental tobacco smoke in the nonsmoking population of Cambodia. Am J Prev Med 2008;34:69-73.

44. Filippidis FT, Agaku IT, Girvalaki C, et al. Relationship of secondhand smoke exposure with sociodemographic factors and smoke-free legislation in the European Union. Eur J Public Health 2016;26:344-9.

45. Oberg M, Jaakkola MS, Prüss-Üstün A, et al. Second hand smoke assessing the burden of disease at national and local levels. WHO Environmental Burden of Disease Series, No. 18. Geneva: WHO, 2010.

46. Li Z, Yao Y, Han W, et al. Smoking prevalence and associated factors as well as attitudes and perceptions towards tobacco control in Northeast China. Int J Environ Res Public Health 2015;12:8606-18.

47. Desalu OO, Onyedum CC, Adewole OO, et al. Secondhand smoke exposure among nonsmoking adults in two Nigerian cities. Ann Afr Med 2011;10:103-11.

48. Lim HK, Ghazali SM, Kee CC, et al. Epidemiology of smoking among Malaysian adult males: prevalence and associated factors. BMC Public Health 2013;13:8.

49. Sureda X, Martínez-Sánchez JM, Fu M, et al. Impact of the Spanish smoke-free legislation on adult, non-smoker exposure to secondhand smoke: cross-sectional surveys before (2004) and after (2012) legislation. PLoS One 2014;9:e89430.

50. Ye X, Yao Z, Gao Y, et al. Second-hand smoke exposure in different types of venues: before and after the implementation of smoke-free legislation in Guangzhou, China. BMJ Open 2014;4:e004273.

51. Azagba S. Effect of smoke-free patio policy of restaurants and bars on exposure to second-hand smoke. Prev Med 2015;76:74-8.

52. Kim J, Ban H, Hwang Y, et al. Impact of partial and comprehensive smoke-free regulations on indoor air quality in bars. Int $J$ Environ Res Public Health 2016;13:754.

53. Fernández E, Fu M, Pérez-Ríos M, et al. Changes in secondhand smoke exposure after smoke-free legislation (spain, 2006-2011) nicotine tob res, 2017. https://doi.org/10.1093/ntr/ntx040

54. Global adult tobacco survey: 2000 Philippines global adult tobacco survey. 2016. http://www.who.int/tobacco/surveillance/2009_gats_ report philippines.pdf?ua=1 (accessed 29 Feb 2016).

55. Teh KX, Ooi JX, Sadasivan S, et al. Perceived effectiveness of policy and legislation on smoking among Malaysian adults. Int $j$ collab res internal me Public Health 2014;6:207-15.

56. Institute for Public Health. National health and morbidity survey 2015 - report on smoking status among Malaysian adults, 2015.

57. Suruhanjaya Perkhidmatan Awam. Pegawai Kesihatan Persekitran/ Penolong Pegawai KesihatanPersekitran. 2017. http://www.spa.gov. my/deskripsi-tugas/ijazah/2750 (accessed 1 Aug 2017).

58. Lopez AD, Collishaw NE, Piha T. A descriptive model of the cigarette epidemic in developed countries. Tob Control 1994;3:242-7.

59. Okoli CT, Kelly T, Hahn EJ. Secondhand smoke and nicotine exposure: a brief review. Addict Behav 2007;32:1977-88.

60. Willemsen MC, Brug J, Uges DR, et al. Validity and reliability of selfreported exposure to environmental tobacco smoke in work offices. J Occup Environ Med 1997;39:1111-4. 